\title{
Intraoperative Hemodynamic and Analgesic Effects of Pre-Incisional Transversus Abdominis Plane Block during Total Abdominal Hysterectomy
}

\author{
Owono Etoundi Paul*, Jéméa Bonaventure, Bengono Bengono Roddy, Tochie Joël, \\ Afané Ela Anatole, Ze Minkandé Jacqueline \\ Department of Surgery and Specialties/Anesthesiology, Faculty of Medicine and Biomedical Sciences, University of Yaoundé 1, \\ Yaoundé, Cameroon \\ Email: ^owonop@gmail.com
}

How to cite this paper: Paul, O.E., Bonaventure, J., Roddy, B.B., Joël, T., Anatole, A.E. and Jacqueline, Z.M. (2017) Intraoperative Hemodynamic and Analgesic Effects of Pre-Incisional Transversus Abdominis Plane Block during Total Abdominal Hysterectomy. Open Journal of Anesthesiology, 7, 393-399.

https://doi.org/10.4236/ojanes.2017.712040

Received: November 2, 2017

Accepted: December 8, 2017

Published: December 11, 2017

Copyright $\odot 2017$ by authors and Scientific Research Publishing Inc. This work is licensed under the Creative Commons Attribution International License (CC BY 4.0).

http://creativecommons.org/licenses/by/4.0/

\begin{abstract}
Background: The efficacy of transversus abdominis plane (TAP) block has been demonstrated in postoperative analgesia, but few studies have evaluated its intraoperative effects. We aimed to describe the intraoperative hemodynamic and analgesic effects of pre-incisional TAP block in patients undergoing total abdominal hysterectomy. Methods: Seventy women proposed for total abdominal hysterectomy indicated for uterine fibroids, classified ASA I and II were randomized in a double-blinded model to Group A $(\mathrm{n}=35)$ receiving bilateral ultrasound-guided TAP block with ropivacaine and Group B $(\mathrm{n}=35)$ receiving bilateral ultrasound-guided TAP block with normal saline, followed by general anesthesia. The variations of the heart rate (HR) and mean arterial blood pressure (MABP) and intraoperative fentanyl consumption were studied. Results: At the arrival in the operating room, there was no significant difference in heart rate and mean arterial pressure noted in both groups. (HR: $85.38 \pm 8.44$ pulsations/min versus $86.30 \pm 10.05$ pulsations $/ \mathrm{min}$, $\mathrm{p}=0.621$; MABP: $94.97 \pm 13.46 \mathrm{mmHg}$ versus $96.36 \pm 12.41 \mathrm{mmHg}, \mathrm{p}=$ $0.533)$. Before surgical incision, no statistically significant difference was detected between the two groups regarding the heart rate and the mean arterial blood pressure. After surgical incision, both the heart rate and mean arterial blood pressure were significantly higher in the Group B. There was a significant decrease in intraoperative fentanyl requirements in the Group A compared to the Group B $(293.58 \pm 60.59 \mathrm{mcg}$ versus $449.44 \pm 71.31 \mathrm{mcg}, \mathrm{p}<$ 0.001). Conclusion: Pre-incisional TAP block attenuates hemodynamic responses to surgical stress and decreases intraoperative fentanyl requirements
\end{abstract}


in patients undergoing total abdominal hysterectomy.

\section{Keywords}

TAP Block, Hemodynamic Effects, Intraoperative Analgesia, Hysterectomy

\section{Introduction}

The Transversus Abdominis Plane (TAP) block is a relatively novel regional anesthetic technique that provides analgesia to the parietal peritoneum as well as the skin and muscles of the anterior abdominal wall [1] [2] [3]. Several recent studies on the management of postoperative pain through a multimodal analgesic regimen clearly show the efficacy of the TAP block in the control of postoperative pain of total abdominal hysterectomy [4] [5] [6]. However, few studies have cited its intraoperative effects. The purpose of this study was to describe the intraoperative hemodynamic and analgesic effects of pre-incisional bilateral TAP block in patients undergoing total abdominal hysterectomy.

\section{Patients and Methods}

\subsection{Patients and Design}

Seventy women aged $31-78$ years of American Society of Anesthesiologists (ASA) classification grade I and II scheduled for elective total abdominal hysterectomy, indicated for uterine fibroids, were enrolled in this study after taking approval from the National Ethics Committee and obtaining a written informed consent from all patients. This study was prospective comparative radomized, double blind, and it was conducted from January 2014 until June 2016 at the Department of Anesthesiology and Intensive Care of the Yaoundé Central Hospital in Cameroon. We excluded obese patients (body mass index $>30 \mathrm{~kg} / \mathrm{m}^{2}$ ), those with cardiovascular diseases, neuropsychiatric disorders and patients on long-term analgesic therapy. Patients with contraindications or known allergies to the drugs used to perform the TAP block were also excluded. The patients were blindly and equally allocated to two groups from a randomization table: Group A and Group B.

\subsection{Anesthesia Protocol}

In GroupA, bilateral ultrasound-guided TAP block was performed in conscious women using ropivacaine $1.5 \mathrm{mg} / \mathrm{kg}$ (diluted in $20 \mathrm{ml}$ normal saline) on each side without exceeding a total dose of $225 \mathrm{mg}$.

In Group B, patients received $20 \mathrm{ml}$ of normal saline injected on both sides through a bilateral ultrasound-guided TAP block.

The drugs administered in the TAP block in both groups were prepared similarly and labelled in syringes bearing a number generated by the randomization process. Neither the anesthesiologist nor surgeon nor nursing team knew the 
group to which each patient belonged. After the realisation of the TAP block, general anesthesia was induced in the patients in the two groups, using propofol $(2.5 \mathrm{mg} / \mathrm{kg})$, fentanyl ( $3 \mathrm{mcg} / \mathrm{kg})$ and rocuronium $(0.9 \mathrm{mg} / \mathrm{kg})$, followed by orotracheal intubation. Ventilation was mechanical. Narcosis was maintained using isoflurane and monitored with the aid of bispectral index; target fixed between 40 and 60. Analgesia was maintained through reinjections of fentanyl (1.5 $\mathrm{mcg} / \mathrm{kg}$ ) when the heart rate and the mean arterial blood pressure increased by more than $20 \%$ with respect to the baseline values. The same Anesthesiologist performed all TAP block, and the total abdominal hysterectomies were performed by the same surgical team and via a Pfannenstiel incision. The same monitor was used for taking heart rate and blood pressure.

\subsection{Statistical Analysis}

We compared the intraoperative variations of the heart rate and the mean arterial blood pressure, and the amount of the analgesics consumed intra-operatively in the two groups. Data analysis was performed using Epi info 3.5.4 statistical software. Means and standard deviations of numerical variables were reported. Categorical variables were analysed using the Fisher's exact test or the Pearson's Chi-square test where appropriate. The threshold for statistical significance was set a p-value less than 0.05 .

\section{Results}

Seventy women undergoing total abdominal hysterectomy completed this study; patients were divided into two equal groups ( 35 patients in each group). Details of allocation, radomization, follow up and final number of patients analysed in the study are represented in Figure 1. No statistically significant difference was detected between the two groups regarding the age, body mass index, ASA status, duration of surgery and duration of anesthesia (Table 1).

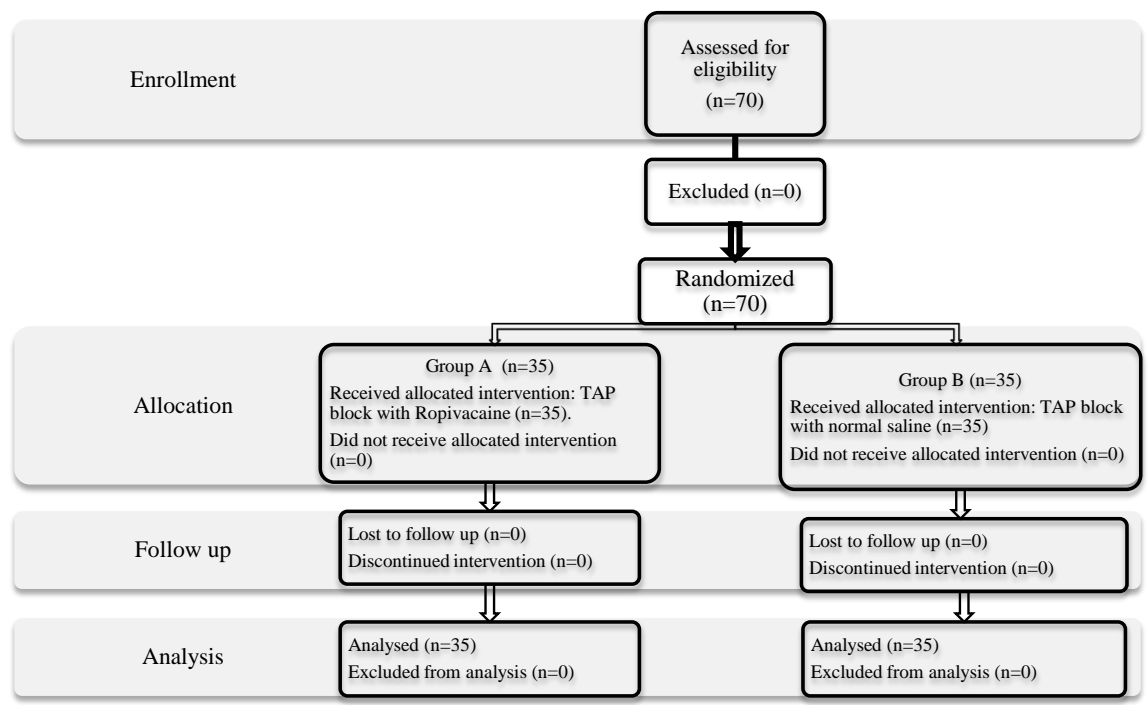

Figure 1. Consort Flow diagram of the studied patients enrolled in the study. 
Table 1. Demographic data and intraoperative characteristics in the two groups.

\begin{tabular}{cccc}
\hline Variables & $\begin{array}{c}\text { Group A }(\mathrm{n}=35) \\
(\text { Mean } \pm \text { SD })\end{array}$ & $\begin{array}{c}\text { Group B }(\mathrm{n}=35) \\
(\text { Mean } \pm \text { SD })\end{array}$ & p-value \\
\hline Age (years) & $48.79 \pm 9.99$ & $47.61 \pm 7.61$ & 0.925 \\
BMI (kg/m²) & $25.53 \pm 2.61$ & $26.18 \pm 2.11$ & 0.333 \\
ASA I/II & $13 / 22$ & $14 / 21$ & 0.914 \\
Duration of surgery (Min) & $86.50 \pm 22.63$ & $94.97 \pm 18.01$ & 0.105 \\
Duration of anesthesia (Min) & $107.55 \pm 27.67$ & $118.30 \pm 18.52$ & 0.148 \\
\hline
\end{tabular}

BMI $=$ body Mass Index; Min $=$ Minutes. ASA $=$ American Society of Anesthesiologists.

Concerning intraoperative hemodynamic parameters, heart rate (HR) and mean arterial blood pressure (MABP) were comparable in the two groups at the arrival in operating room (HR: $85.38 \pm 8.44$ beats/min versus $86.30 \pm 10.05$ beats/min, $\mathrm{p}=0.621$; MABP: $94.97 \pm 13.46 \mathrm{mmHg}$ versus $96.36 \pm 12.41 \mathrm{mmHg}$, $\mathrm{p}=0.533$ ). Before surgical incision, no statistically difference was detected between the two groups regarding the heart rate and the mean arterial blood pressure. After surgical incision, both the heart rate and mean arterial blood pressure were significantly higher in the Group B (Table 2, Figure 2 and Figure 3). There was a significant decrease in intraoperative fentanyl requirement in the Group A compared to the Group B $(293.58 \pm 60.59$ mcg versus $449.44 \pm 71.31$ mcg, $\mathrm{p}<0.001)$.

\section{Discussion}

TAP block is a new regional anesthetic technique, which is increasingly being used and adopted worldwide. This anesthetic technique provides good analgesia to the skin and musculature of the anterior abdominal wall in patients undergoing various abdominal surgeries [7] [8] [9] [10] [11]. In this study, we assessed the intra-operative hemodynamic and analgesic effects of the TAP block on a cohort of patients undergoing total abdominal hysterectomy via a Pfannenstiel incision. Our findings suggest that the ropivacaine TAP block performed prior to surgical incision attenuates hemodynamic responses to surgical stress as illustrated by a significant reduction in heart rate and mean arterial blood pressure values following surgical incision in the Group A compared to the Group B (Table 2, Figure 2 and Figure 3), corroborating with results obtained by Bhattacharjee et al. [12].

Furthermore, we found that TAP block with ropivacaine reduced intraoperative pain as evident by the reduction in fentanyl consumption in the Group A compared to the Group B $(293.58 \pm 60.59 \mathrm{mg}$ versus $449.44 \pm 71.31 \mathrm{mcg}, \mathrm{p}<$ 0.001 ). This may be explained by the synergistic interaction between the ropivacaine TAP block and intravenous fentanyl to potentiate intraoperative analgesic effects in Group A. These results concur with those of Bhattacharjee et al. [12] who observed a significant decline in the intraoperative consumption offentanyl in the bupivacaine TAP block group compared to the placebo group (81 


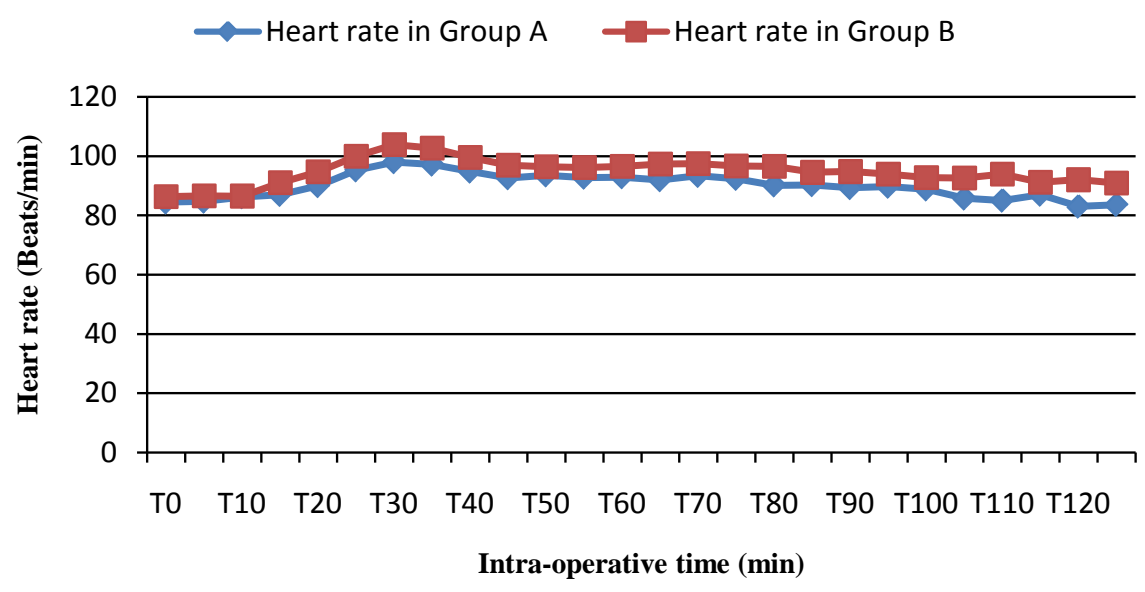

Figure 2. Intraoperative mean heart rate in the two groups. T0: Arrival in operating room; T5: Induction of TAP block; T10: Induction of general anesthesia; T20: Surgical incision.

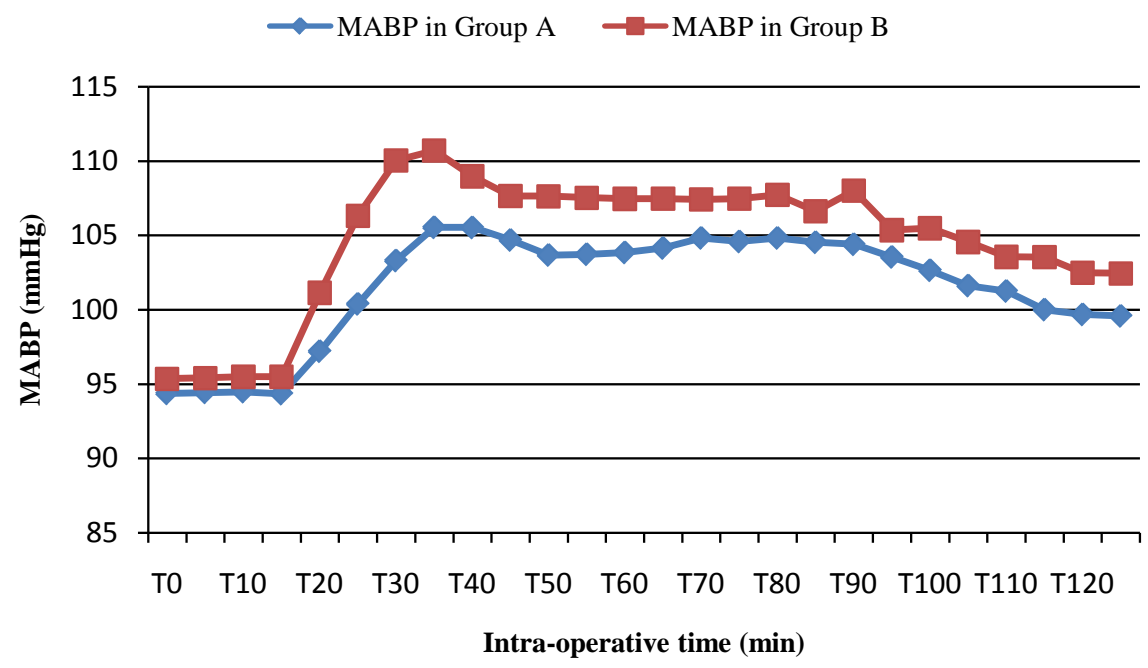

Figure 3. Intraoperative mean arterial blood pressure (MABP) in the two groups. T0: Arrival in operating room; T5: Induction of TAP block; T10: Induction of general anesthesia; T20: Surgical incision.

Table 2. Comparison of intraoperative hemodynamic parameters in the two groups.

\begin{tabular}{ccccccc}
\hline \multirow{2}{*}{$\begin{array}{c}\text { Operatives } \\
\text { Parameters }\end{array}$} & $\begin{array}{c}\text { Group A } \\
(\text { Mean } \pm \text { SD })\end{array}$ & $\begin{array}{c}\text { Group B } \\
(\text { Mean } \pm \text { SD })\end{array}$ & p-value & $\begin{array}{c}\text { Group A } \\
(\text { Mean } \pm \text { SD })\end{array}$ & $\begin{array}{c}\text { Group B } \\
(\text { Mean } \pm \text { SD })\end{array}$ & p-value \\
\hline $\begin{array}{c}\text { Heart rate } \\
(\text { Beats/min })\end{array}$ & $85.38 \pm 8.44$ & $86.30 \pm 10.05$ & 0.621 & $93.20 \pm 7.42$ & $99.91 \pm 11.48$ & 0.007 \\
$\begin{array}{c}\text { MABP } \\
(\mathrm{mmHg})\end{array}$ & $94.97 \pm 13.46$ & $96.36 \pm 12.41$ & 0.533 & $100.38 \pm 13.36$ & $110.30 \pm 13.70$ & 0.004 \\
\hline
\end{tabular}

Min $=$ Minutes, MABP $=$ Mean Arterial Blood Pressure.

versus $114 \mathrm{mcg}, \mathrm{p}<0.001)$ during total abdominal hysterectomy. Likewise, Mukhtar et al. [13] also found a drop in intraoperative need of fentanyl (0.4 \pm 
1.2 versus $9.3 \pm 1.4 \mathrm{mg}, \mathrm{p}<0.0001)$ in renal recipient patients who had a bupivacaine TAP block prior to renal transplantation. More still, bupivacaine TAP block administered prior to laparoscopic cholecystectomy has been shown to significantly reduce the intraoperative demand for morphine-like drugs [14] [15].

The most important clinical implication of our study is a significant reduction in the consumption of intraoperative morphine-like drugs associated with ropivacaine TAP block use. This finding is of invaluable economic interest in our resource-constrained environment where morphine-like drugs are often scant and relatively expensive. Likewise, the reduced intraoperative hemodynamic fluctuations associated with the ropivacaine TAP block provide a safe intraoperative analgesic option for patients with cardiovascular diseases who are intolerant to tachycardia or other hemodynamic variations.

We acknowledge some limitations of our study. Despite monitoring of the level of anesthesia using the bispectral index in conjunction with adequate myorelaxation and anticipation of hypovolemia, the indirect assessment of intraoperative pain by measuring the heart rate and mean arterial blood pressure might have introduced some bias in the appreciation of the efficacy of intraoperative analgesia.

\section{Conclusion}

Pre-incisional TAP block attenuates hemodynamic responses to surgical stress and decreases intraoperative fentanyl requirements in patients undergoing total abdominal hysterectomy. This regional anesthetic technique uses simple anatomical landmarks to provide a safe and efficacious intraoperative analgesia.

\section{Conflict of Interest}

The authors declare that they have no conflicts of interest in relation with this article.

\section{Acknowledgements}

We would like to thank all the study participants for accepting to partake in this study.

\section{References}

[1] Webster, K. (2008) The Transversus Abdominis Plane (TAP) Block: Abdominal Plane Regional Anaeshesia. Update in Anaesthesia, 24, 24-29.

[2] Beloeil, H. and Zetlaoui, P.J. (2011) TAP bloc et bloc de la paroi abdominale. Annales Françaises d' Anesthésie et de Réanimation, 30, 141-146. https://doi.org/10.1016/j.annfar.2010.12.015

[3] Young, M.J., Gorlin, A.W., Modest, V.E. and Quraishi, S.A. (2012) Clinical Implications of the Transversus Abdominis Plane Block in Adults. Anesthesiology Research and Practice, $11 \mathrm{p}$.

[4] Petersen, P.L., Mathiesen, O., Torup, H. and Dahl, J.B. (2010) The Transversus Ab- 
dominis Plane Block: A Valuable Option for Postoperative Analgesia? A Topical Review. Acta Anaesthesiologica Scandinavica, 54, 529-535. https://doi.org/10.1111/j.1399-6576.2010.02215.x

[5] Kishore, H., Raghavan, P., Chacko, L., Puthur, S.B. and Ancy (2014) Comparision of Analgesic Efficacy of TAP Block with Parentral Opioid Following Total Abdominal Hysterectomy. Journal of Evidence Based Medicine and Healthcare, 1, 2121 2128. https://doi.org/10.18410/jebmh/2014/306

[6] Arbel, R., Stanleigh, J. and Loscovich, A. (2013) Pain Management Following Abdominal Hysterectomy, Novel Approaches and Review of Literature. Journal of Clinical Gynecology and Obstetrics, 2, 51-55. https://doi.org/10.4021/jcgo130w

[7] McDonnell, J.G., O’Donnell, B., Curley, G., Heffernan, A., Power, C. and Laffey, J.G. (2007) The Analgesic Efficacy of Transversus Abdominis Plane Block after Abdominal Surgery: A Prospective Randomized Controlled Trial. Anesthesia \& Analgesia, 104, 193-197. https://doi.org/10.1213/01.ane.0000250223.49963.0f

[8] Berger, J. and Amasse, L. (2010) TAP Bloc: Réalisation, Indications. Le Praticien en Anesthésie Réanimation, 14, 37-42. https://doi.org/10.1016/j.pratan.2010.01.009

[9] Heriche, C., Blot, R.M. and Dubost, C. (2010) TAP Block: Enfin un bloc de paroi abdominale simple et efficace? MAPAR, 43-56.

[10] McDonnel, J.G., Curley, G., Carney, J., Benton, A., Costello, J., Maharaj, C.H. and Laffey, J.G. (2008) The Analgesic Efficacy of Transversus Abdominis Plane Block after Cesarian Delivery: A Randomized Controlled Trial. Anesthesia \& Analgesia, 106, 186-191. https://doi.org/10.1213/01.ane.0000290294.64090.f3

[11] Carney, G., McDonnell, J.G., Ochana, A., Bhinder, R. and Laffey, J.G. (2008) The Transversus Abdominis Plane Block Provides Effective Postoperative Analgesia in Patients undergoing total Abdominal Hysterectomy. Anesthesia \& Analgesia, 107, 2056-2060. https://doi.org/10.1213/ane.0b013e3181871313

[12] Bhattacharjee, S., Ray, M., Ghose, T., Maitra, S. and Layek, A. (2014) Analgesic Efficacy of Transversus Abdominis Plane Block in Providing Effective Perioperative analgesia in Patients Undergoing Total Abdominal Hysterectomy: A Randomized Controlled Trial. Journal of Anaesthesiology Clinical Pharmacology, 30, 391-396. https://doi.org/10.4103/0970-9185.137274

[13] Mukhtar, K. and Khattak, I. (2010) Transversus Abdominis Plane Block for Renal Transplant Recipients. British Journal of Anaesthesia, 104, 663-664. https://doi.org/10.1093/bja/aeq077

[14] EL-Dawlatly, A.A., Turkistani, A., Kettner, S.C., Machata, A.M., Delvi, M.B., Thallaj, A., et al. (2009) Ultrasound-Guided Transversus Abdominis Plane Block: Description of a New Technic and Comparison with Conventional Systemic Analgesia during Laparoscopic Cholecystectomy. British Journal of Anaesthesia, 102, 763-767. https://doi.org/10.1093/bja/aep067

[15] Ra, Y.S., Kim, C.H., Lee, G.Y. and Han, J.I. (2010) The Analgesic Effect of the Ultrasound-Guided Transversus Abdominis Plane Block after Laparoscopic Cholecystectomy. Korean Journal of Anesthesiology, 58, 362-368.

https://doi.org/10.4097/kjae.2010.58.4.362 